\title{
REPLACEMENT OF THE PROXIMAL AORTA AND AORTIC VALVE USING A COMPOSITE BILEAFLET PROSTHESIS AND GELATIN-IMPREGNATED POLYESTER GRAFT (CARBO-SEAL): EARLY RESULTS IN 143 PATIENTS
}

\author{
Stephen M. Langley, FRCS ${ }^{a}$ \\ Stephen J. Rooney, FRCS ${ }^{\mathrm{b}}$ \\ Malcolm J. R. Dalrymple-Hay, FRCS ${ }^{\mathrm{a}}$ \\ Jonathan M. F. Spencer, FRCS ${ }^{\mathrm{a}}$ \\ Michael E. Lewis, FRCS ${ }^{b}$ \\ Domenico Pagano, FRCS ${ }^{b}$ \\ Mohammed Asif, FRCS ${ }^{b}$ \\ Jonathan R. Goddard, MSc ${ }^{c}$ \\ Victor T. Tsang, FRCS ${ }^{\mathrm{a}}$ \\ Robert K. Lamb, FRCS ${ }^{a}$ \\ James L. Monro, FRCS ${ }^{a}$ \\ Steven A. Livesey, FRCS ${ }^{a}$ \\ Robert S. Bonser, FRCS ${ }^{b}$
}

\begin{abstract}
Objective: We report the combined early results from two centers in the United Kingdom using a composite conduit consisting of a bileaflet mechanical valve incorporated into a gelatin-impregnated, ultra-low porosity, woven polyester graft (Carbo-Seal; Sulzer Carbomedics, Inc, Austin, Tex). Methods: Between August 1992 and March 1997, 143 patients underwent aortic root replacement with the Carbo-Seal composite prosthesis. The indication for surgery was acute type A dissection in $31(22 \%)$, chronic type $A$ dissection in $9(6 \%)$, ascending aortic aneurysm without dissection in $100(70 \%)$, and false aneurysm of the ascending aorta in $3(2 \%)$. Twenty-seven patients $(19 \%)$ had undergone previous sternotomy, and $40(28 \%)$ were seen as emergencies. Concomitant procedures were performed in 38 (27\%), including 18 aortic arch or hemiarch replacements. Total follow-up is $\mathbf{2 7 0}$ patient-years. Follow-up is $\mathbf{1 0 0 \%}$ complete. Results: The early (30-day) mortality was 7\% (10 patients). Permanent neurologic events occurred in 2\%. At a mean follow-up of $\mathbf{2 3}$ months, $\mathbf{9 4 \%}$ of survivors were in New York Heart Association functional class I. Freedom from reoperation was 97.2\% \pm $1.6 \%$ (1 standard error [1 SE]) at 12 months and $95.7 \% \pm 2.2 \%$ at 48 months. Including early mortality, survival was $90.1 \% \pm 2.6 \%$ at 12 months and $83.1 \% \pm 3.5 \%$ at 48 months. Conclusions: Aortic root replacement with use of the Carbo-Seal prosthesis can be undertaken with a relatively low early mortality and morbidity. A low reoperation rate and high intermediate-term survival can be expected, but continued follow-up is needed to determine the long-term efficacy of this prosthesis. (J Thorac Cardiovasc Surg 1999;118:1014-20)
\end{abstract}

S ince Bentall and De Bono's first description of the use of a composite graft and valve for the complete replacement of an ascending aortic aneurysm and aortic valve, ${ }^{1}$ both the techniques of implantation and the types of valve and graft used have evolved. The currently preferred implantation technique, a modified

From the Wessex Cardiothoracic Centre, ${ }^{\text {a }}$ Southampton General Hospital, Southampton, United Kingdom, Cardiothoracic Surgical Unit, ${ }^{\text {b }}$ Queen Elizabeth Hospital, Edgbaston, Birmingham, United Kingdom, and Medical Statistics and Computing, ${ }^{c}$ University of Southampton, Southampton General Hospital, Southampton, United Kingdom.

Received for publication Oct 9, 1998; revisions requested Jan 28, 1999; revisions received July 7, 1999; accepted for publication Aug 11, 1999.

Address for reprints: Stephen M. Langley, Wessex Cardiothoracic Centre, Southampton General Hospital, Southampton, United Kingdom, SO16 6YD (E-mail: StephenLangley@dial.pipex.com). Copyright (C) 1999 by Mosby, Inc.

0022-5223/99 $\$ 8.00+0 \quad \mathbf{1 2 / 1 / 1 0 2 0 8 5}$
Bentall procedure, involves excision of the aneurysm, implantation of a composite valve graft with direct attachment of the coronary arteries as buttons into the aortic graft and anastomosis of the graft distally to the divided aorta. ${ }^{2}$ Woven polyester has become the material of choice for most surgeons for prosthetic aortic replacement. Bleeding through the earlier porous grafts was a particular problem, and the classic inclusion technique was specifically designed to cope with this by making use of the aneurysm sac as a wrap-around to tamponade graft leakage. Grafts that required preclotting with albumin or blood have now been superceded by woven polyester impregnated with either collagen or gelatin, ${ }^{3,4}$ resulting in a prosthesis resistant to blood leakage through its interstices, one described as having ultra-low porosity.

More recently, composite prostheses for replacing the aortic root have become commercially available, and one such composite conduit is the Carbo-Seal ascend- 
Table I. Indication for operation

\begin{tabular}{lc}
\hline Indication for operation & No. of patients $(\%)$ \\
\hline Ascending aortic aneurysm & $100(70)$ \\
Acute type A dissection & $27(19)$ \\
Acute type A redissection & $4(3)$ \\
Chronic type A dissection & $9(6)$ \\
False ascending aortic aneurysm & $3(2)$ \\
Total & 143 \\
\hline
\end{tabular}

ing aortic prosthesis (Sulzer Carbomedics, Inc, Austin, Tex). The prosthesis combines a bileaflet CarboMedics prosthetic heart valve with a gelatin-impregnated, woven polyester graft. There is minimal tapering between the valve and the graft, which facilitates coronary implantation, especially where coronary mobilization is difficult (eg, in redo cases). The graft is retained by the titanium stiffening ring of the valve (Fig 1). The impregnation of the graft with gelatin confers ultra-low porosity and apart from simple washing, the graft needs no special treatment before implantation. The aim of this study was to retrospectively review the cases of all patients who underwent aortic root replacement with the Carbo-Seal prosthesis at two surgical centers in the United Kingdom and to determine risk factors for early mortality and the prevalence of early morbid events, as well as the intermediate term survival and freedom from reoperation.

\section{Patients and methods}

Between August 1992 and March 1997, 143 consecutive patients underwent aortic root replacement with the CarboSeal ascending aortic prosthesis at the Wessex Cardiothoracic Centre, in Southampton, United Kingdom (76 patients), and the Queen Elizabeth Hospital, in Birmingham, United Kingdom (67 patients). The indication for a Carbo-Seal prosthesis implantation was all patients requiring aortic root replacement, excluding those with an absolute contraindication to anticoagulation and those with an aortic root abscess in whom a homograft aortic root was used. The mean age of the patients was $56.4 \pm 15.8$ years $(1 \mathrm{SD})$. There were 112 males $(78 \%)$ and 31 females (22\%), and Marfan syndrome was present in 27 (19\%). Preoperatively, 58 patients were in New York Heart Association (NYHA) functional class I (40\%), 28 in class II $(20 \%), 36$ in class III $(25 \%)$, and 21 in class IV (15\%). The diagnosis was made by means of a combination of echocardiography, aortography, and computed tomographic and magnetic resonance imaging, depending on the degree of urgency and local availability. Coronary angiography was undertaken in 92 patients (64\%), though not in those with acute dissection or young patients without risk factors for coronary artery disease. Annuloaortic ectasia

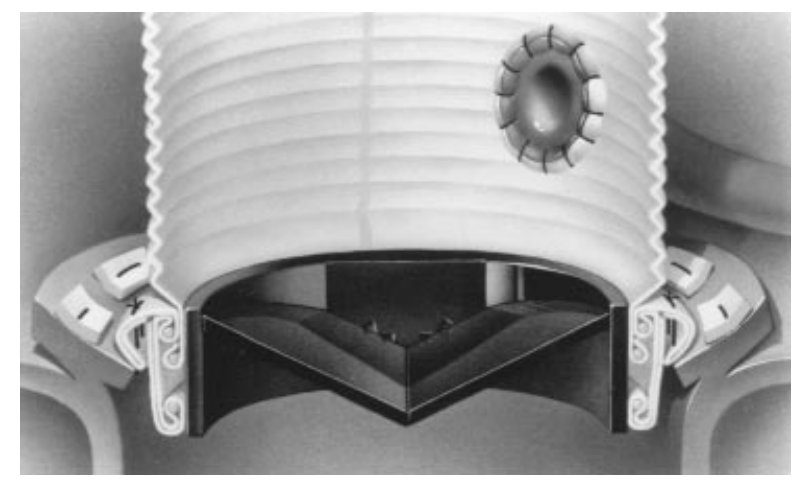

Fig 1. Incorporation of the graft into the valve housing.

(comprising dilatation of the aorta at valve and sinus level and cephalad migration of the coronary ostia) was considered to be present in the 27 patients with Marfan syndrome and in a further 85 patients with histologic evidence of cystic medial degeneration. The indications for surgery are given in Table I. The four patients classified as having a redissection had all previously undergone ascending aortic replacement with an interposition graft for aortic dissection and had subsequently redissected in the proximal aorta, resulting in aortic regurgitation. Of the 3 patients with a false aneurysm, 1 had undergone a total of 5 aortic valve replacements for infective endocarditis, 1 had undergone an aortic root replacement 7 years previously, and the third had undergone repair of a type A dissection and resuspension of the aortic valve 4 years earlier.

Twenty-seven patients (19\%) had undergone previous cardiac surgery requiring sternotomy. Aortic valve replacement (AVR) had been undertaken in 15 patients, aortic root replacement in 5, an ascending aortic interposition graft in 5, AVR and coronary artery bypass grafting in 1 , and correction of tetralogy of Fallot in 1 . Ten of the 40 patients (25\%) with type A dissection had undergone previous aortic valve or ascending aortic surgery. Concomitant procedures were undertaken in 38 patients $(27 \%)$. Twelve patients underwent aortic arch replacement, and concomitant hemiarch replacement was undertaken in 6 , coronary artery bypass grafting in 13 , and other procedures in 7 . Surgery was undertaken as an emergency in 40 patients $(28 \%$ ), on an urgent basis (the next available operating list) in 17 (12\%), and electively in 86 (60\%).

Operative details. A total of 143 patients underwent aortic root replacement with the Carbo-Seal ascending aortic prosthesis by a modification of the Bentall technique. ${ }^{1}$ Tight wrapping of the aortic aneurysm sac around the graft was not done owing to its association with late complications, ${ }^{5}$ but loose wrapping was used occasionally as an aid to hemostasis. Redundant aortic tissue was excised, and the distal anastomosis was made to the divided aorta. Coronary reimplantation was performed by using the button technique ${ }^{6}$ for 140 patients, by the inclusion technique for 2 patients, and by the Cabrol technique for 1 patient. $^{7}$ The prosthesis has an ade- 
Table II. Causes of early mortality

\begin{tabular}{lccl}
\hline Day & Sex & Age & \multicolumn{1}{c}{ Cause of death } \\
\hline DOT & M & 74 & Acute cardiac failure \\
DOT & M & 59 & Acute myocardial infarction \\
12 hours & F & 49 & Acute myocardial infarction \\
1 & M & 68 & Acute cardiac failure \\
5 & M & 66 & Ruptured abdominal aortic aneurysm \\
7 & M & 74 & Stroke from atheromatous embolism \\
8 & M & 80 & Multiorgan failure \\
9 & F & 74 & Multiorgan failure \\
15 & M & 71 & Sepsis \\
19 & M & 70 & Acute myocardial infarction \\
\hline
\end{tabular}

DOT, Death on table.

quate sewing cuff as well as a graft that is easy to suture and does not fray when the coronary ostia are fashioned with a battery-operated cautery device.

The diameter of the aortic anulus determines the size of the prosthesis implanted. For valve sizes 21 to 31, the graft inner diameter is $3 \mathrm{~mm}$ larger than the valve size, and for a prosthesis with a valve size of $33 \mathrm{~mm}$, the graft size is $34 \mathrm{~mm}$. In this series a prosthesis with valve size of $23 \mathrm{~mm}$ was implanted in 27 patients (19\%), size 25 was used in 54 patients $(38 \%)$, size 27 in 30 patients $(21 \%)$, and size 29 in 32 patients (22\%). Gelatin-resorcin-formaldehyde tissue glue was used in $78(55 \%)$ of cases. It was used in all patients with acute aortic dissection to facilitate apposition of layers of the dissected aorta at the distal anastomosis and in other cases to cover the anastomotic suture lines as determined by the individual surgeon's preference. The mean duration of cardiopulmonary bypass was $129 \pm 49$ minutes, the mean ischemic time was $88 \pm 29$ minutes, and a variety of perfusion techniques were used. The femoral artery was cannulated in 127 patients (89\%), the distal ascending aorta in $16(11 \%)$. Venous return was established via the right atrium in 125 patients $(87 \%)$ and the femoral vein in $18(13 \%)$. Cold crystalloid potassium cardioplegic solution was given antegradely in $137(96 \%)$ and retrogradely in 6 patients. Moderate hypothermia $\left(28^{\circ} \mathrm{C}\right)$ was used in 84 patients $(59 \%)$. Deep hypothermia $\left(15^{\circ} \mathrm{C}-18^{\circ} \mathrm{C}\right)$ with circulatory arrest was used in 59 patients $(41 \%)$. It was always used in patients undergoing repair of acute dissection or aortic arch surgery. The mean duration of circulatory arrest was $26 \pm 14$ minutes. Retrograde cerebral perfusion was used in 45 of these patients, with a mean duration of $23 \pm 14$ minutes. Aprotinin was used in 57 cases $(40 \%)$.

All patients received anticoagulation with warfarin. This was commenced on the evening of the first postoperative day. The international normalized ratio (INR) was maintained between 2.5 and 3.5. If the INR had not reached the therapeutic range by day 3 postoperatively, then intravenous heparin was commenced and the activated partial thromboplastin ratio was also maintained between 2.5 and 3.5. Anti-platelet medication was not routinely prescribed. After patients were discharged from the hospital, their clinical status was obtained either from outpatient clinic visits to the hospital or by directly contacting the patient's family doctor by letter and questionnaire. The total follow-up was 270 patient-years. Followup was $100 \%$ complete.

Statistical analysis. All continuous data are expressed as mean \pm 1 SD or median \pm interquartile range; categorical variables are reported as a percentage; a commercial statistical software package (SPSS for Windows, version 8.0, SPSS Inc, Chicago, Ill) was used for data analysis. A total of 26 preoperative and operative variables were analyzed for their possible influence on early mortality (defined as occurring within 30 days of operation or anytime before discharge). The preoperative variables were age, sex, previous cardiac surgery, preoperative NYHA class, cardiac rhythm, creatinine, presence of a pericardial effusion, left ventricular function, urgency of surgery, and indication for surgery. Operative variables included the operating surgeon, arterial and venous cannulation sites, type of cardioplegia, valve size implanted, use of tissue glue, aprotinin, lowest temperature, use of circulatory arrest, retrograde cerebral perfusion, concomitant procedure, aortic crossclamp and cardiopulmonary bypass time, use of an intra-aortic balloon pump, blood loss in the first 24 hours, and length of stay on the intensive care unit. Variables were first tested individually in a univariate logistic regression analysis. Subsequently, covariates found to be either significant $(P<.05)$ or possibly significant $(P<.2)$ were then entered into a multivariable logistic regression model. Survival and freedom from reoperation probability estimates were determined by Kaplan-Meier actuarial analysis; variability was expressed as \pm 1 SEM.

\section{Results}

Early mortality. The early (30-day) mortality was $7 \%$ (10 patients). The causes of death are detailed in Table II. Of these 10 patients, 6 had undergone emergency surgery for acute type A dissection, 6 had undergone previous aortic or cardiac surgery, 7 had a concomitant procedure, and 6 were in NYHA class IV preoperatively. Three patients had acute myocardial infarction, resulting in early death. In no case was this related to technical problems with the coronary anastomoses. Two of these patients had severe underlying coronary artery disease. One had an acute infarction peroperatively and could not be weaned from cardiopulmonary bypass. The other had an unheralded MI 19 days postoperatively. The patient's INR on the previous day was 3.2. The third patient who died of an acute myocardial infarction had received $5 \mathrm{~g}$ of tranexamic acid peroperatively, and acute coronary ostial thrombosis developed 12 hours postoperatively. The patient presented in cardiac arrest, and despite rapid institution of resuscitation, including commencement of cardiopulmonary bypass and coronary artery bypass grafting, the patient died. Six factors were found to be 
Table III. Risk factors for early death

\begin{tabular}{lccr}
\hline Risk factor & $\begin{array}{c}\text { No } \\
\text { Early death } \\
(n=10)\end{array}$ & $\begin{array}{c}\text { early death } \\
(n=133)\end{array}$ & P value \\
\hline Age (y) & $68.5 \pm 8.9$ & $55.4 \pm 15.8$ & .023 \\
NYHA class IV & $60 \%$ & $11 \%$ & $<.001$ \\
Creatinine (mmol/L) & $131 \pm 44$ & $105 \pm 28$ & .014 \\
Concomitant procedure & $70 \%$ & $23 \%$ & .004 \\
Cardiopulmonary & $203 \pm 79$ & $123 \pm 42$ & $<.001$ \\
$\quad$ bypass time (min) & & & .011 \\
Emergency surgery & $60 \%$ & $21 \%$ &. \\
\hline
\end{tabular}

Data for continuous variables are given as mean \pm standard deviation; categorical variables are reported as a percentage.

significantly associated $(P<.05)$ with early death (Table III). By multiple logistic regression, however, only cardiopulmonary bypass time was found to be associated with increased early mortality in the presence of the other factors $(P=.03)$. The odds ratio for cardiopulmonary bypass time was 1.0236 (95\% confidence interval 1.0022 to 1.0456 ).

Early morbidity. Postoperative complications developed in 68 patients $(47.6 \%)$. There were a total of 83 early morbid events in this group (Table IV). Of the 14 patients returned to surgical theater because of bleeding, a "surgical" source was identified in only 3 and in no case was the bleeding related to the prosthesis. The mean blood loss through the drains in the first 24 hours was 720 $\pm 552 \mathrm{~mL}$. There were 3 permanent neurologic complications, all of which were present at extubation, comprising 2 patients with hemiplegia and 1 with mild left arm weakness. Two patients had a transient ischemic attack, with transient upper limb weakness developing shortly after extubation on the first postoperative day. In both cases the deficit fully recovered within a few hours, and neither patient has had any further episode. Respiratory failure, defined as a need for mechanical ventilation for more than 24 hours, occurred in 11 patients. Two patients who required hemofiltration because of acute tubular necrosis made a full recovery. Both patients who suffered sternal dehiscence had developed a wound infection with methicillin-resistant Staphylococcus aureus. One healed after undergoing sternal resuture and wound irrigation; the other required an omental transposition. Six patients had a pyrexia of unknown origin develop. This diagnosis was made only when repeated cultures of sputum, urine, wound, and blood were negative, the white cell count was not elevated, echocardiographic appearances were normal, and the patient was clinically well. The median intensive care unit stay was 1 day (interquartile range, 12 days). Median hospital stay was 11 days (interquartile range, 8-16 days).
Table IV. Early morbidity

\begin{tabular}{lc}
\hline Early morbidity & No. of patients \\
\hline Cardiac complications & 46 \\
Atrial fibrillation or flutter & 18 \\
Returned for bleeding & 14 \\
Permanent pacemaker & 8 \\
Pericardial effusion requiring drainage & 6 \\
Neurologic complications & 7 \\
Cerebrovascular accident (permanent) & 3 \\
Cerebrovascular accident (temporary) & 2 \\
Transient ischemic attack & 2 \\
Respiratory complications & 16 \\
Respiratory failure & 11 \\
Bronchopneumonia & 4 \\
Pleural effusion requiring drainage & 1 \\
Renal complications & 2 \\
Hemofiltration (temporary) & 2 \\
Wound complications & 4 \\
Sternal dehiscence & 2 \\
Wound infection & 2 \\
Fever of unknown origin & 6 \\
Gastrointestinal bleeding requiring laparotomy & 1 \\
Recurrent laryngeal nerve palsy & 1
\end{tabular}

Table V. Causes of late mortality

\begin{tabular}{|c|c|c|c|c|}
\hline & Age/Sex & Mo & Postmortem & Cause of death \\
\hline 1. & 70 Male & 2 & No & Cerebrovascular accident \\
\hline 2. & 74 Male & 5 & No & Cerebrovascular accident \\
\hline 3. & 46 Male & 5 & Yes & Intracranial bleeding \\
\hline 4. & 76 Male & 10 & No & $\begin{array}{l}\text { Multisystem failure } \\
\text { following redo for } \\
\text { endocarditis }\end{array}$ \\
\hline 5. & 76 Male & 12 & No & Cerebrovascular accident \\
\hline 6. & 44 Male & 12 & No & Myocardial failure \\
\hline 7. & 79 Male & 29 & No & Cerebrovascular accident \\
\hline
\end{tabular}

Late results. The mean duration of follow-up was 23 \pm 17 months (maximum, 56 months). Of the 126 surviving patients, 119 (94.4\%) are in NYHA class I, with the remaining 7 (5.6\%) in NYHA class II. There were 7 late deaths. The causes of the deaths of these patients are detailed in Table V. Four patients died of cerebrovascular accident (CVA). One of these patients had a permanent CVA develop perioperatively. The patient was subsequently transferred home, where he died 5 months later. The other 3 patients whose cause of death was CVA did not have a peroperative CVA and died at other hospitals; unfortunately, none of them underwent autopsy. The 46-year-old man who died as a result of intracranial bleeding had this diagnosed on postmortem examination. Finally the 44-year-old man who died 12 months postoperatively had undergone 4 previous aortic valve 


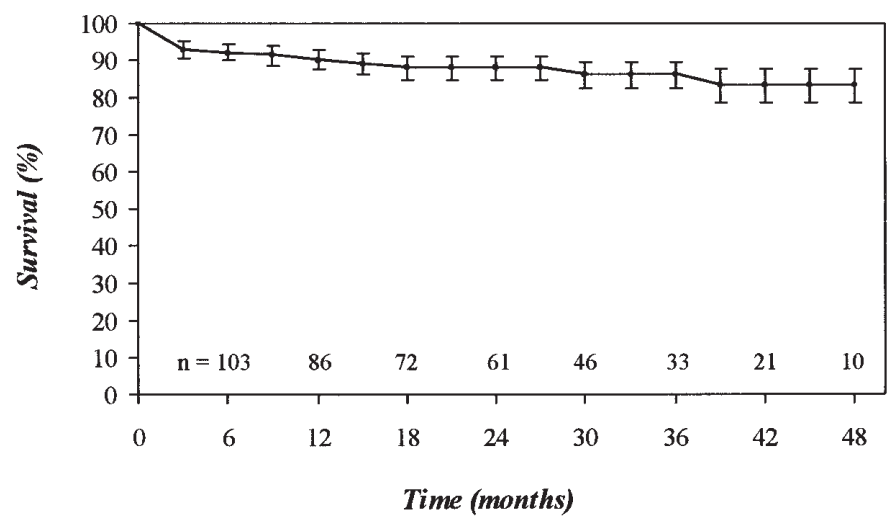

Fig 2. Kaplan-Meier survival curve.

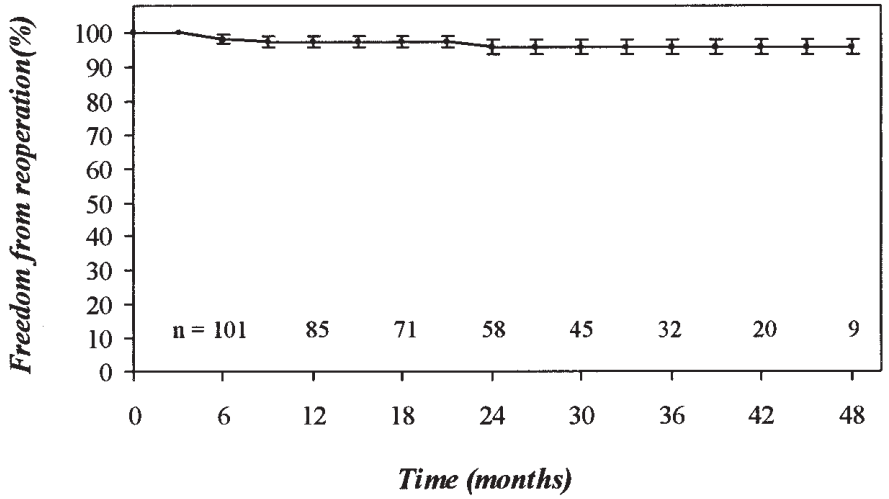

Fig 3. Freedom from reoperation.

replacements for endocarditis and a homograft aortic root replacement before his Carbo-Seal aortic root replacement. The indication for the Carbo-Seal aortic root replacement was a false aneurysm. He had a long history of alcohol abuse and was in NYHA class III as a result of alcoholic cardiomyopathy. He was seen, moribund, 12 months after the Carbo-Seal implantation, and transesophageal echocardiography demonstrated a small leak from around the right coronary button. There was no evidence of valve dysfunction. In view of his history and moribund condition, further surgery was not thought appropriate. Including early mortality, survival was $90.1 \% \pm 2.6 \%(1 \mathrm{SE})$ at 12 months, $87.9 \% \pm 3.0 \%$ at 24 months, and $83.1 \% \pm 4.4 \%$ at 48 months (Fig 2). Freedom from reoperation was $97.2 \% \pm 1.6 \%$ (1 SE) at 12 months and $95.7 \% \pm 2.2 \%$ at 48 months (Fig 3). Four patients have undergone reoperation:

1. A 30-year-old man had infective endocarditis develop 117 days postoperatively and underwent a homograft aortic root replacement. He is currently alive and well and in NYHA class I.
2. A 71-year-old woman in whom a false aneurysm developed at the distal aortic suture line 153 days postoperatively, which necessitated repair on cardiopulmonary bypass though the prosthesis, did not need a replacement prosthesis. She is currently alive and in NYHA class II.

3. A 76-year-old man had endocarditis, including a large aortic root abscess, 256 days after aortic root and hemiarch replacement. Homografts were used to replace the root and arch, but the patient died of multisystem failure 29 days later.

4. A 26-year-old man with Marfan syndrome who had undergone a classical Bentall operation had a false aneurysm arising from the right coronary ostium. At 687 days postoperatively, a Carbo-Seal prosthesis was used with the button technique for the coronary anastomoses. He is currently well and in NYHA class I.

With regard to nonfatal valve-related complications, there were 2 patients who underwent reoperation for endocarditis, as discussed above. In addition, 3 patients had amaurosis fugax and began low-dose aspirin thera- 
py and had no recurrence. There was no other reported incidence of valve-related complications during follow-up-no valve dysfunction, valve thrombosis, thrombotic embolism, or bleeding event.

\section{Discussion}

Composite valve and graft replacement of the aortic root has become the generally accepted surgical technique for treatment of a variety of proximal aortic conditions, including aneurysm with aortic valve incompetence, aortic dissection, and infective endocarditis. Controversy exists, however, in the case of both aortic dissection and aneurysmal dilatation, particularly in patients with Marfan syndrome. Some favor aortic root replacement ${ }^{8,9}$; others advocate the sparing of the aortic valve leaflets, even when aortic insufficiency is present, because they believe the valve dysfunction is caused by dilatation of the sinotubular junction, distortion of the sinuses of Valsalva, or annuloaortic ectasia. ${ }^{10}$ Currently, we elect to replace the entire aortic root, including the valve, in such patients. No patients in this series underwent root replacement for treatment of endocarditis where a homograft would be our choice.

The Carbo-Seal prosthesis was chosen because of the surgeons' familiarity with CarboMedics prosthetic heart valves (Sulzer Carbomedics, Inc). A meta-analysis of CarboMedics prosthetic aortic valves has revealed excellent functional characteristics in combination with 5-year freedoms from thrombosis, thromboembolism, endocarditis, and reoperation of $100 \%$, 94\%, 98\%, and $97 \%$, respectively. ${ }^{11}$ The woven polyester Carbo-Seal graft is impregnated with cross-linked mammalian gelatin. The gelatin biodegrades by hydrolysis within 14 days. In collagen-coated grafts, however, the collagen is enzymatically metabolized and the rate of removal of collagen has been shown to be slower than that of gelatin. ${ }^{3}$ Previous studies have shown the gelatin to be nonpyrogenic and to exhibit low thrombogenicity. In addition, no inflammatory reaction was induced, as determined by plasma $\mathrm{C}$-reactive protein and $\alpha_{1}$-acid glycoprotein., ${ }^{3,12}$ Collagen-coated grafts, however, have been shown to stimulate an increased inflammatory response arising from the incompletely absorbed collagen coating. ${ }^{13}$ Six patients (4\%) had a fever of unknown origin postoperatively, which resolved in all of them within 2 weeks. Although this may be related to an inflammatory response produced by the gelatin, experimental evidence suggests that this is not the case, ${ }^{3}$ and these fevers may reflect mediastinal collections of blood around the graft.

The early mortality in this series of $7 \%$ compares with that of between $5 \%$ and $13 \%$ in other similar series. ${ }^{2,6,14-19}$ Direct comparison between these series is difficult, however, as the patient groups vary between the series. The number of emergencies, dissections, reoperations, and patients with Marfan's syndrome all vary, as do the surgical techniques and prostheses used. On initial inspection, the incidence of early morbid events may seem high. In part, this probably reflects the thorough nature of this study and, in part, the relatively high-risk nature of the surgery itself. The most important complications from the patient's standpoint, however, are those with long-term effects. These include a permanent pacemaker ( 8 patients), permanent neurologic deficit (3 patients), and omental transfer for sternal dehiscence in a patient with methicillin-resistant $S$. aureus infection.

Late complications were infrequent, given the complex nature of the surgery. Two patients had endocarditis develop, necessitating replacement of the prosthesis with a homograft. Two patients had a false aneurysm, 1 at the distal anastomosis, which was repaired without replacing the aortic root, and 1 from the right coronary artery button, after a classic Bentall procedure. This has been reported by others and seems to be associated with Bentall's inclusion technique ${ }^{5}$ - probably the result of tension on the coronary ostial anastomoses resulting from the wrapping, particularly when blood accumulates within the wrap. ${ }^{14}$ Our results give further support to other series advocating the button technique ${ }^{6,17}$ as no pseudoaneurysms have developed in the proximal aortic area when this technique has been used.

Actuarial survival of $83.1 \% \pm 4.4 \%$ at 4 years compares very favorably with other series, $2,6,18,19$ including those in which higher risk patients, such as with emergency cases, have been excluded. ${ }^{16}$ Our series, however, has relatively few patients reaching 4 years' followup at present. Thromboembolism may occur more frequently after prosthetic aortic root replacement when compared with simple aortic valve replacement. Gott and associates ${ }^{20}$ found the incidence of minor thromboembolic and hemorrhagic events to be low (0.42\% per 100 patient-years in a study of 270 patients), whereas Peigh and associates ${ }^{21}$ reported a very high incidence of scotoma (50\%) in a small group of patients with valve-conduit replacements. Amaurosis fugax was reported to us in 3 cases. None of the 4 patients whose cause of death was given as CVA underwent autopsy.

In conclusion, aortic root replacement using the Carbo-Seal ascending aortic prosthesis is effective treatment for aortic aneurysms and dissections involving the aortic root, both as a primary procedure and in patients undergoing a redo operation. The technique of aortic 
resection and direct coronary button implantation results in a relatively low operative mortality and morbidity, together with a high freedom from reoperation. In that the current study only addresses early and intermediate outcome, continued follow-up will be needed to determine the long-term efficacy of this prosthesis.

\section{REFERENCES}

1. Bentall $\mathrm{H}$, De Bono A. A technique for complete replacement of the ascending aorta. Thorax 1968;23:338-9.

2. Hilgenberg AD, Akins CW, Logan DL, Vlahakes GJ, Buckley MJ, Madsen JC, et al. Composite aortic root replacement with direct coronary artery implantation. Ann Thorac Surg 1996;62: 1090-5.

3. Drury JK, Ashton TR, Cunningham JD, Maini R, Pollock JG. Experimental and clinical experience with a gelatin impregnated Dacron prosthesis. Ann Vasc Surg 1987;1:542-7.

4. Westaby S, Parry A, Giannopoulos N, Pillai R. Replacement of the thoracic aorta with collagen-impregnated woven Dacron grafts: early results. J Thorac Cardiovasc Surg 1993;106:427-33.

5. Kouchoukos NT, Marshall WG, Jr, Wedige-Stecher TA. Elevenyear experience with composite graft replacement of the ascending aorta and aortic valve. J Thorac Cardiovasc Surg 1986;92: 691-705.

6. Svensson LG, Crawford ES, Hess KR, Coselli JS, Safi HJ. Composite valve graft replacement of the proximal aorta: comparison of techniques in 348 patients. Ann Thorac Surg 1992;54: 427-39.

7. Cabrol C, Pavie A, Gandjbakhch I, Villemot JP, Guiraudon G, Laughlin L, et al. Complete replacement of the ascending aorta with reimplantation of the coronary arteries: new surgical approach. J Thorac Cardiovasc Surg 1981;81:309-15.

8. Bachet JE, Termignon JL, Dreyfus G, Goudot B, Martinelli L, Piquois A, et al. Aortic dissection: prevalence, cause, and results of late reoperations. J Thorac Cardiovasc Surg 1994;108:199206.

9. Fann JI, Glower DD, Miller DC, Yun KL, Rankin JS, White WD, et al. Preservation of aortic valve in type A aortic dissection com- plicated by aortic regurgitation. J Thorac Cardiovasc Surg 1991; 102:62-75.

10. David TE, Feindel CM, Bos J. Repair of the aortic valve in patients with aortic insufficiency and aortic root aneurysm. J Thorac Cardiovasc Surg 1995;109:345-52.

11. Akins CW. Results with mechanical cardiac valvular prostheses. Ann Thorac Surg 1995;60:1836-44.

12. Vohra R, Drury JK, Shapiro D, Shenkin A, Pollock JG. Sealed versus unsealed knitted Dacron prostheses: a comparison of the acute phase protein response. Ann Vasc Surg 1987;1:548-51.

13. Jonas RA, Schoen FJ, Levy RJ, Castaneda AR. Biological sealants and knitted Dacron: porosity and histological comparisons of vascular graft materials with and without collagen and fibrin glue pretreatments. Ann Thorac Surg 1986;41:657-63.

14. Aoyagi S, Kosuga K, Akashi H, Oryoji A, Oishi K. Aortic root replacement with a composite graft: results of 69 operations in 66 patients. Ann Thorac Surg 1994;58:1469-75.

15. Coselli JS, Crawford ES. Composite valve-graft replacement of aortic root using separate Dacron tube for coronary artery reattachment. Ann Thorac Surg 1989;47:558-65.

16. Jault F, Nataf P, Rama A, Fontanel M, Vaissier E, Pavie A, et al. Chronic disease of the ascending aorta. Surgical treatment and long-term results. J Thorac Cardiovasc Surg 1994;108:747-54.

17. Kouchoukos NT, Wareing TH, Murphy SF, Perrillo JB. Sixteenyear experience with aortic root replacement: results of 172 operations. Ann Surg 1991;214:308-20.

18. Lewis CT, Cooley DA, Murphy MC, Talledo O, Vega D. Surgical repair of aortic root aneurysms in 280 patients. Ann Thorac Surg 1992;53:38-46.

19. Lytle BW, Mahfood SS, Cosgrove DM, Loop FD. Replacement of the ascending aorta: early and late results. J Thorac Cardiovasc Surg 1990;99:651-8.

20. Gott VL, Gillinov AM, Pyeritz RE, Cameron DE, Reitz BA, Greene PS, et al. Aortic root replacement: risk factor analysis of a seventeen-year experience with 270 patients. J Thorac Cardiovasc Surg 1995;109:536-45.

21. Peigh PS, DiSesa VJ, Cohn LH, Collins JJ Jr. Neurological and ophthalmological phenomena after aortic conduit surgery. Circulation 1990;82(5 Suppl):IV47-50. 